NASA Technical Memorandum 89821

AIAA-87-2138

\title{
Agreement Between Experimental and Theoretical Effects of Nitrogen Gas Flowrate on Liquid Jet Atomization
}
(NASA-TM-8982 1) AGREENENT EETWEEN
EXEERIMENTAL AND THEORETICAL EIFECTS OF
NITROGEN GAS FLOWFATE CN LICUID JET
ATOMIZATICN (NASA) $11 \mathrm{~F}$
CSCL 20D
Onclas 43507

N87-1 $196 \varepsilon 4$

Robert D. Ingebo

Lewis Research Center

Cleveland, Ohio

Prepared for the

23rd Joint Propulsion Conference

cosponsored by the AIAA, ASEE, ASME, and SAE

San Diego, California, June 29-July 2, 1987 
AGREEMENT BETWEEN EXPERIMENTAL AND THEORETICAL EFFECTS OF NITROGEN GAS FLOWRATE ON LIQUID JET ATOMIZATION

Robert D. Ingebo

National Aeronautics and Space Administration

Lewis Research Center

Cleveland, Ohio 44135

\section{Abstract}

Two-phase flows were investigated by using high velocity nitrogen gas streams to atomize smalldiameter liquid jets. Tests were conducted primarily in the acceleration-wave regime for liquid jet atomization, where it was found that the loss of droplets due to vaporization had a marked effect on drop size measurements. In addition, four identically designed two-fluid atomizers were fabricated and tested for similarity of spray profiles. A scattered-light scanner, developed at NASA Lewis Research Center, was used to measure a characteristic drop diameter, $D_{C}$, which was correlated with $n$ itrogen $g$ as flowrate, $W_{n}$, in the expression $D_{c}^{-1}=k W_{n}^{n}$. $D_{c}$ may be expressod as volume median,

$D_{v .5}$, Sauter mean, $D_{32}$, or volume-linear mean, $\mathrm{D}_{31}$, drop diameter. At a distance of $2.2 \mathrm{~cm}$ downstream from the atomizer and a water flowrate of $3.15 \mathrm{~g} / \mathrm{sec}$, the following expressions were obtained: $D_{v .5}^{-1}=240 w_{n}^{1.33}, D_{32}^{-1}=320 w_{n}^{1.33}, D_{31}^{-1}=400 w_{n}^{1.33}$, where $D_{C}$ and $W_{n}$ are given in centimeters and grams per second, respectively. The exponent of 1.33 for nitrogen gas flowrate is identical to that predicted by atomization theory for 1 iquid jet breakup in the acceleration-wave regime. This is higher than the value of 1.2 which was previously obtained at a sampling distance of $4.4 \mathrm{~cm}$ downstream of the atomizer. The difference is attributed to the fact that drop-size measurements obtained at a $2.2 \mathrm{~cm}$ sampling distance are less effected by vaporization and dispersion of small droplets and therefore should give better agreement with atomization theory. Profiles of characteristic drop diameters were also obtained by making at least five line-of-sight measurements across the spray at several horizontal positions above and below the center line of the spray. Comparisons of spray symmetry of $D_{y}^{\prime} .5$ profiles were made for the four identical atomizers and values of $0 y .5$ obtained near the spray center line were found to be considerably higher than the overall values of $0_{v} .5$ obtained for the entire spray.

\section{Introduction}

In an experimental investigation of two-phase interacting-flows, characteristic drop diameters and spray profile data were obtained for small liquid jets atomized with high velocity nitrogen gas streams. A recently improved scattered-light scanner, developed at the NASA Lewis Research Center, was used to obtain the drop size data. The instrument was primarily designed to study smal1-droplet sprays with Sauter mean diameters in the order of $10 \mu \mathrm{m}$. Such sprays are useful in simulating clouds for icing research and combustion studies of rapidly vaporizing fuel sprays. At present, very little data are available on small-droplet sprays due to difficulties involved, in producing and measuring characteristic drop sizes in the order of $10 \mu \mathrm{m}$.

When a liquid jet is injected into an airstream, both atomization and vaporization can occur simultaneously. In order to determine the initial drop size of a spray from data obtained downstream of an atomizer, the effect of vaporization on the drop size must be known. In Ref. 1, the effect of mass velocity of the nitrogen gas flow, $\rho_{n} V_{n}$, on the volume median drop diameter, $D_{V} .5$ was determined and it was found that $D_{v .5} \sim\left(\rho_{n} v_{n}\right)-0.8$ at a sampling distance of $25 \mathrm{~cm}$ downstream of the atomizer. In a later study, ${ }^{2}$ values of $D_{v} .5$ were determined at $4.4 \mathrm{~cm}$ downstream of the atomizer and it was found that $D_{V .5} \sim\left(o_{n} V_{n}\right)-1.2$. The decrease in the exponent from -1.2 to -0.8 , when sampling distance is increased from 4.4 to $25 \mathrm{~cm}$, was attributed to the effect of vaporization on the drop size measurements.

From the study reported in Ref. 2 , it was found that drop size data should be taken as close to the atomizer as possible in order to minimize vaporization effects. As a result, the present study was undertaken primarily to obtain drop size data even closer to the atomizer orifice to determine if the exponent for $\rho_{n} V_{n}$ would continue to increase as axial sampling distance decreased. If a sample were taken too close to the atomizer, however, the exponent for $o_{n} V_{n}$ could also decrease due to incomplete formation of the liquid into droplets.

To investigate the effect of aerodynamic forces on characteristic drop sizes of atomized liquid jets, the scattered-light scanner originally described ${ }^{1}$ was modified for use in the present study. It was modified not only to measure the overall drop size characteristics of the spray but also to obtain several line-of-sight drop size profiles at various sampling locations downstream of the atomizer. For this measurement, the laser beam size was decreased and by adjusting the atomizer up and down from the center line, at least five lineof-sight measurements were obtained across the spray cross section. The instrument was also used to obtain exponents for the Rosin-Rammier and Nukiyama-Tanasawa drop size distribution expressions.

In the present study, values of the volumelinear mean drop diameter, $D_{31}$, were measured with the scattered-light scanner as well as exponents for the two drop size distribution expressions mentioned above. All of the sprays were formed in a low velocity, $5 \mathrm{~m} / \mathrm{sec}$, airflow to aid in transporting small drops through the laser beam. Liquid and gas pressures for the atomizers were varied over a range of 0.2 to $1.0 \mathrm{MPa}$ and the resulting sprays were sampled at distances of $2.2,4.4$, and $6.7 \mathrm{~cm}$ downstream of the atomizer orifice.

\section{Nomenclature}

drop size parameter in Nukiyama-Tanasawa expression, $\mathrm{cm}$ 
drop size parameter in Rosin-Rammler expression, $\mathrm{cm}$

$D_{C} \quad$ characteristic drop diameter measured for entire spray, $\mathrm{cm}$

$D_{c}^{\prime} \quad$ characteristic drop diameter for

line-of-sight measurements, cm

$\mathrm{D}_{i} \quad$ diameter of ith drop, $\mathrm{cm}$

$\mathrm{D}_{\mathrm{v} .5}$ volume median drop diameter, $\mathrm{cm}$

$\mathrm{D}_{32}$ Sauter mean drop diameter, $\sum_{\mathrm{i}} \mathrm{nD}_{\mathrm{i}}^{3}$ /

$\sum_{i} n D_{i}^{2}, \mathrm{~cm}$

$\mathrm{D}_{31}$ volume-linear mean drop diameter, $\left[\sum_{i} \mathrm{nD}_{i}^{3} /\right.$

$\left.\sum_{i} \mathrm{nD}_{i}\right]^{0.5}, \mathrm{~cm}$

k correlation coefficient, $\mathrm{sec} / \mathrm{g}-\mathrm{cm}$

$N_{n}$ exponent for Nukiyama-Tanasawa drop size distribution expression

$\mathrm{N}_{r}$ exponent for Rosin-Rammler drop size distribution expression

n number of droplets

$v \quad$ volume fraction of droplets having diameter $x$

W weight flow of fluid, $1 \mathrm{~b} / \mathrm{sec}$ or $\mathrm{g} / \mathrm{sec}$

$x \quad$ droplet diameter in drop size distribution expressions, $\mathrm{cm}$

$\bar{x} \quad$ axial downstream spray sampling distance, $\mathrm{cm}$

Subscripts

n nitrogen gas

w water

\section{Apparatus and Procedure}

The test section, scattered-light scanner, and auxiliary equipment are shown in Fig. 1 . Air supplied at ambient temperature, $293 \mathrm{~K}$, passed through the $0.24 \mathrm{~m}$ inside diameter test section which exhausted to the atmosphere. The test section was $1 \mathrm{~m}$ in length and a $5.08 \mathrm{~cm}$ diameter orifice was used to measure airflow rate in the test section. With a control valve, an airstream velocity of $5 \mathrm{~m} / \mathrm{sec}$ was maintained in the test section to aid in transporting small droplets through the laser beam.

To study liquid jet breakup, a pneumatic twofluid atomizer with assist nitrogen gas flow was used to produce clouds of small droplets. The atomizer shown in Fig. 2 was mounted at the center 1 ine of the $24 \mathrm{~cm}$ diameter duct and operated over pressure ranges of 0.2 to $1.0 \mathrm{MPa}$ for both water and nitrogen gas. Water sprays were injected downstream into the airflow just upstream of the duct exit. The sprays were sampled at distances of 2.2 , 4.4 , and $6.7 \mathrm{~cm}$ downstream of the atomizer orifice with the 4.4 by $1.9 \mathrm{~cm}$ rectangular laser beam. A diagram of the atomizers used in the present study is shown in $\mathrm{Fig}$. 3. They were designated as $\mathrm{S}-4$,
S-14, S-53, and S-94 and all were fabricated from the same design.

Water at a temperature of $293 \mathrm{~K}$, measured with an I.C. thermocouple, was axially injected into the airstream by gradually opening a control valve until the desired flow rate was obtained as indicated by a turbine flowmeter. Nitrogen gas was then turned on to atomize the water jet and weight flowrate was measured with a $0.51 \mathrm{~cm}$ diameter sharp edge orifice. After air, nitrogen, and water flowrates were set, volume median and other characteristic drop diameters and exponents for drop size distribution expressions were determined using the scatteredlight scanner. The optical system is shown in $\mathrm{Fig.} \mathrm{2.} \mathrm{It} \mathrm{consisted} \mathrm{of} \mathrm{a} \mathrm{1-mW} \mathrm{helium-neon} \mathrm{laser,}$ a 0.003-cm-diameter aperture, a 7.5-cm-diameter collimating lens, a 10-cm-diameter converging lens, a 5-cm-diameter collecting lens, a scanning disk with a $0.05-\mathrm{cm}$ slit, a timing light, and a photomultiplier detector.

The spatial resolution of the scattered-1ight scanner is $2.86 \mathrm{~cm}$ and corresponds to the laser beam diameter. A sufficient volume of each spray was sampled to minimize spray pattern effects when measuring characteristic mean drop diameters for the entire spray. Effects of the drop size distribution function on scattered-light scanner measurements is discussed in detail. ${ }^{3}$ It was found ${ }^{3}$ that the irradiance distribution is on ly weakly related to the particle diameter distribution function, and therefore, irradiance distribution was used to determine characteristic drop diameters and changes in the drop size distribution function were assumed to have a negligible effect on drop size measurements. Reproducibility tests gave experimental measurements of drop size that agreed within \pm 5 percent. Five sets of monosized polystyrene spheres having diameters of $8,12,25,50$, and $100 \mu \mathrm{m}$, were used to calibrate the scattered-light scanner. A more complete description of the scattered-light scanner, the mean drop diameter range, and the method of determining mean or median particle diameter can be found in Refs. 3 and 4 .

Tests were made with four pneumatic two-fluid atomizers fabricated from the same design and the volume median, $D_{v} .5$, the Sauter mean, $D_{32}$, and the volume-linear mean, $D_{31}$, drop diameters were measured with the scattered-light scanner. The entire cloud of droplets was sampled at three axial locations downstream of the atomizers. Also, line-ofsight profiles of characteristic drop diameters were obtained to determine the spatial dispersion of the spray as a function of the nitrogen gas flowrate, water flowrate, and the spray sampling distance downstream of the atomizer. Drop-size distribution exponents for both the Rosin-Rammler and the Nukiyama-Tanasawa expressions were also determined with the scattered-light scanner.

\section{Experimental Results}

The four atomizers were initially tested at an axial downstream distance of $4.4 \mathrm{~cm}$. The effect of axial sampling distance on characteristic drop size was then investigated and a comparison was made of three characteristic drop size expressions.

Finally, line-of-sight profi?es of the characteristic drop diameter, $D_{v}, 5$, were obtained for each of the four atomizers. Characteristic exponents 
for Rosin-Rammler and Nukiyama-Tanasawa drop-size distribution expressions were also determined.

Comparisons of Performance of Similar Atomizers

Volume median drop diameters produced by the four atomizers S-4, S-14, S-53, and S-94 were measured with the scattered-light scanner. All four atomizers were constructed from the design shown in Fig. 3. In Fig. 4(a) to (d), the reciprocal of the volume median drop diameter $0_{V}^{-1} .5$, is plotted versus nitrogen gas flowrate. Water flowrate was varied from 3.15 to $9.46 \mathrm{~g} / \mathrm{sec}$ and the drop size data were obtained at a distance of $4.4 \mathrm{~cm}$ downstream of the atomizer. From these plots, the following general expression was derived for the four

atomizers: $D_{\vec{v}}^{-1} \cdot 5 \sim w_{n}^{1} \cdot 2$. In order to compare their atomizing performance, the following expressions were derived for atomizers $S-4, S-14, S-53$, and S-94, respectively: $D_{v .5}^{-1}=310 w_{n}^{1.2}, D_{v .5}^{-1}=$ $293 w_{n}^{1.2}, D_{v .5}^{-1}=277 w_{n}^{1.2}$, and $D_{v .5}^{-1}=300 w_{n}^{1.2}$ where the correlation coefficient, $k$, was evaluated at a constant water flowrate of $3.15 \mathrm{~g} / \mathrm{sec}$, and $\left.D_{v}^{-1}\right]_{5}$ is given in $\mathrm{cm}^{-1}$. The highest and lowest values of $k$ differ by approximately 10 percent. This variation between atomizers is somewhat greater than desired in the design of an array of atomizers for application in a combustor or an icing wind tunnel and it was attributed to variations in physical dimensions of the atomizers such as tubing size and the $0.32 \mathrm{~cm}$ diameter orifice.

Effect of Axial Sampling Distance on Characteristic Drop Size

The entire spray was sampled at axial distances of $x=2.2,4.4$, and $6.7 \mathrm{~cm}$ where $\bar{x}$ is the distance from the atomizer orifice to the center line of the laser beam as measured along the spray center line. Water flowrate was held approximately constant at $3.15 \mathrm{~g} / \mathrm{sec}$ and characteristic drop diameters, $D_{v} .5$ and $D_{32}$, were measured and plotted against $n$ itrogen gas flowrate, $W_{n}$, as shown in Figs. $5(a)$ and $(b)$. All of the atomizers were used for this series of tests, and the data plotted in Fig. $5($ a) show that:

$$
\begin{aligned}
& D_{v .5}^{-1} \sim w_{n}^{1.33} \\
& D_{v .5}^{-1} \sim w_{n}^{1.2} \\
& D_{v .5}^{-1} \sim w_{n}^{1.0}
\end{aligned}
$$

at values of $\bar{x}=2.2,4.4$, and $6.7 \mathrm{~cm}$, respectively. Figure $5(\mathrm{~b})$ gives similar results for the Sauter mean diameter, $\mathrm{D}_{32}$.

In the preceding expressions, $D_{v} .5 \sim W_{n}^{1} .33$ as obtained at $\bar{x}=2.2 \mathrm{~cm}$, agrees with that qiven by atomization theory for liguid jet breakup in the acceleration-wave regime. 5

Measurements ubtained at $\bar{x}=2.2 \mathrm{~cm}$ are 1 ess affected by vaporization and dispersion of the very small droplets as compared with measurements made farther downstream from the atomizer orifice. Values of the exponent, $n$, obtained in other experimental studies are also shown in Table 1 for comparison with atomization theory.

Comparison of Characteristic Drop Size Expressions

Characteristic drop diameters, $\mathrm{D}_{v_{3}}, \mathrm{D}_{32}$, and $\mathrm{D}_{31}$, were determined using atomizer $5-94$ to produce sprays which were sampled at downstream distances of $\bar{x}=2.2,4.4$, and $6.7 \mathrm{~cm}$. In Figs. $6(\mathrm{a})$ to $(\mathrm{c})$ the reciprocals of the characteristic drop diameters $\mathrm{D}_{\mathrm{v} .5}^{-1}, \mathrm{D}_{32}^{-1}$, and $\mathrm{D}_{31}^{-1}$ with units of $\mathrm{cm}^{-1}$ are

plotted against nitrogen gas flowrate raised to the exponent a, which was determined from $F$ ig. 5 as a function of the spray sampling distance $\bar{x}$. From the plots shown in Fig. 6, the values of the correlation coefficient $k$ were determined and the following general expression was derived:

$$
\mathrm{D}_{\mathrm{C}}^{-1}=k \mathrm{w}_{\mathrm{n}}^{\mathrm{a}}
$$

where $D_{C}$ is a characteristic drop diameter. At the sampling distance of $\bar{x}=2.2 \mathrm{~cm}$, the following expressions were ob+ained:

$$
\begin{aligned}
& D_{v .5}^{-1}=240 w_{n}^{1.33} \\
& D_{32}^{-1}=320 w_{n}^{1.33} \\
& D_{31}^{-1}=400 w_{n}^{1.33}
\end{aligned}
$$

The correlation coefficient, $k$, and nitrogen gas flowrate exponent, a, are given in Table 2 for comparison. It is interesting to note that at any of the three sampling distances, the value of $k$ var$i$ ed by only about \pm 6 percent whereas the exponent a changed from 1.33 to 1.0 when $\bar{x}$ was increased from 2.2 to $6.7 \mathrm{~cm}$. These results indicate that vaporization and dispersion of the small drops had only a minor effect on the correlation coefficient $k$ but a major effect on the exponent $a$.

\section{Profiles of Characteristic Drop Diameter, D'v. 5}

The beam height of the scattered-light scanner was reduced from 4.4 to $0.64 \mathrm{~cm}$ and ine-of-sight measurements of the characteristic drop diameter were obtained at several horizontal locations in each spray. Measurements were obtained for the four atomizers $S-4, S-14, S-53$, and $S-94$ and values of $D_{v, 5}^{\prime}$ are plotted against horizontal location as shown in Fig. 7. The spray profile data were obtained for the four atomizers at constant water and nitrogen gas flowrates and an axial downstream sampling distance of $\bar{x}=4.4 \mathrm{~cm}$.

Peak values of $D_{y}^{\prime} 5$ at the liquid jet center 1 ine were reduced near $1 y 50$ percent, from approximately 60 to $30 \mu \mathrm{m}$, when the nitrogen gas flowrate was increased from 1.59 to $2.59 \mathrm{~g} / \mathrm{sec}$. A similar reduction in $D_{v}^{\prime} 5$ occurred near the upper and lower fringes of the sprays. The asymmetry of the spray profiles was attributed to the effect of gravity on the drops and also to slight misalignments of the center tubes of the various atomizers. values of $D_{V}^{\prime} .5$ show relatively good uniformity of drop size for the four atomizers. Differences in values of $D_{v}^{\prime} 5$ for the four atomizers were in the order of 10 to 20 percent. 
Characteristic Exponents for Drop-Size Distribution Expressions

The scattered-1ight scanner gave data for the exponent $N_{r}$, which appears in the Rosin-Rammler expression as follows:

$$
\frac{d v}{d x}=\frac{N_{r} x^{N_{r}-1}}{c^{N^{N}}} e^{-(x / c)^{N_{r}}}
$$

Data were also obtained for the exponent $N_{n}$, which appears in the Nukiyama-Tanasawa expression as follows:

$$
\frac{d v}{d x}=\frac{b^{6 / N_{n}}}{\Gamma\left(6 / N_{n}\right)} x^{5} e^{-b x^{N_{n}}}
$$

From a plot of the data obtained with the four atomizers, as shown in Fig. 8 the following relation was determined:

$$
N_{r}=2.8 N_{n}^{0.45}
$$

which is the same as that derived in Ref. 1 . Thus it was found that although the ciownstream distance, $x$, was varied from 2.2 to $6.7 \mathrm{~cm}$, the relation between the exponents was not appreciably affected by vaporization and dispersion of the small drop lets.

\section{Concluding Remarks}

When characteristic drop diameters of water sprays were measured with the scattered-light scanner at a distance of $2.2 \mathrm{~cm}$ downstream of the orifice of a pneumatic two-fluid atomizer, values of $\mathrm{D}_{\mathrm{v} .5}^{-1}, \mathrm{D}_{32}^{-1}$, and $\mathrm{D}_{31}^{-1}$ were obtained that could be correlated with nitrogen gas flowrate raised to the 1.33 power. This exponent of 1.33 is the same as that derived theoretically in Ref. 5 for liquid jet atomization in the acceleration-wave breakup regime. The fact that experimental results agreed with atomization theory was attributed to a negligible loss of small droplets due to vaporization and dispersion affects. These affects were not negligible at a distance of $6.7 \mathrm{~cm}$ downstream of the atomizer orifice, where the exponent decreased to a value of 1.0 . When the laser beam was positioned at a distance of less than $2.2 \mathrm{~cm}$ from the atomizer characteristic drop diameters increased markedly due to incomplete breakup of the liquid jet. With atomizer S-94, at a water flowrate of $3.15 \mathrm{~g} / \mathrm{sec}$ and a sampling distance of $2.2 \mathrm{~cm}$, the following expressions for characteristic drop diameter of the initial spray were obtained:

$$
\begin{aligned}
& D_{v .5}^{-1}=240 w_{n}^{1.33} \\
& D_{32}^{-1}=320 w_{n}^{1.33} \\
& D_{31}^{-1}=400 w_{n}^{1.33}
\end{aligned}
$$

which agree well with atomization theory.
Profiles of characteristic drop diameters were a lso determined from 1 ine-of-sight measurements made with the scattered-light scanner. Such data are useful in comparing the performance of similar atomizers by providing information concerning the spatial dispersion of drop size characteristics within the spray cross secticn. Reproducibility of the spray data were within \pm 5 percent. Also, it was found that experimental values of the exponents $N_{n}$ and $N_{r}$, for the drop-size distribution expressions, were not appreciably affected when the sampling distance, $x$, was varied from 2.2 to $6.7 \mathrm{~cm}$ downstream of the atomizer orifice.

\section{References}

1. Ingebo, R.D., "Formation and Characterization of Simulated Small Droplet Clouds," AIAA Paper 86-0409, Jan. 1986.

2. Ingebo, R.D., "Characterization of Simulated Small-Droplet Fuel Sprays, " AIAA Paper 86-1725, Jan. 1986.

3. Buchele, D.R., "Scanning Radiometer for Measurement of Forward-Scattered Light to Determine Mean Diameter of Spray Particles, NASA TM $x-3454,1976$.

4. Buchele, D.R., "Particle Sizing by Measurement of Forward-Scattered Light at Two Angles, "NASA TP-2156, 1983.

5. Adelberg, M., "Mean Drop Size Resulting from the Injection of a Liquid Jet into a High-Speed Gas Stream," AIAA Journal, Vol. 6, No. 6, June 1968, pp. 1143-1147.

6. Weiss, M.A., and Worsham, C.H., "Atomization in High Velocity Airstreams," American Rocket Society Journal, Vol. 29, No. 4, Apr. 1959, pp. 252-259.

7. Wolfe, H.E., and Andersen, W.H., "Aerodynamic Break-up of Liquid Drops," Proceedings of the 5 th International Shock Tube Symposium, Z.I. Slawsky, J.F. Moulton $\mathrm{Jr}_{\text {. }}$, and W.S. Filler, Eds., Naval Ordnance Lab., White Oak, MD, 1965, pp. 1145-1169. (Avail NTIS, $A D-638011$.

8. Kim, K.Y., and Marshall, W.R. Jr., "Drop Size Distributions from Pneumatic Atomizers," AIChE Journal, Vol. 17, No., 3, May 1971, pp. 575-584.

9. Nukiyama, S., and Tanasawa, Y., "Experiments on the Atomization of Liquids by Means of an Air Stream, Parts III-IV," Transactions of the Society of Mechanical Engineers, Japan, Vol. 5, No. 18, Feb. 1939, pp. 63-75.

10. Lorenzetto, G.E., and Lefebvre, A.H., "Measurements of Drop Size on a Plain-Jet Airblast A tomizer," AIAA Journal, Vol. 15, No. 7, July 1977, pp. 1006-1010. 


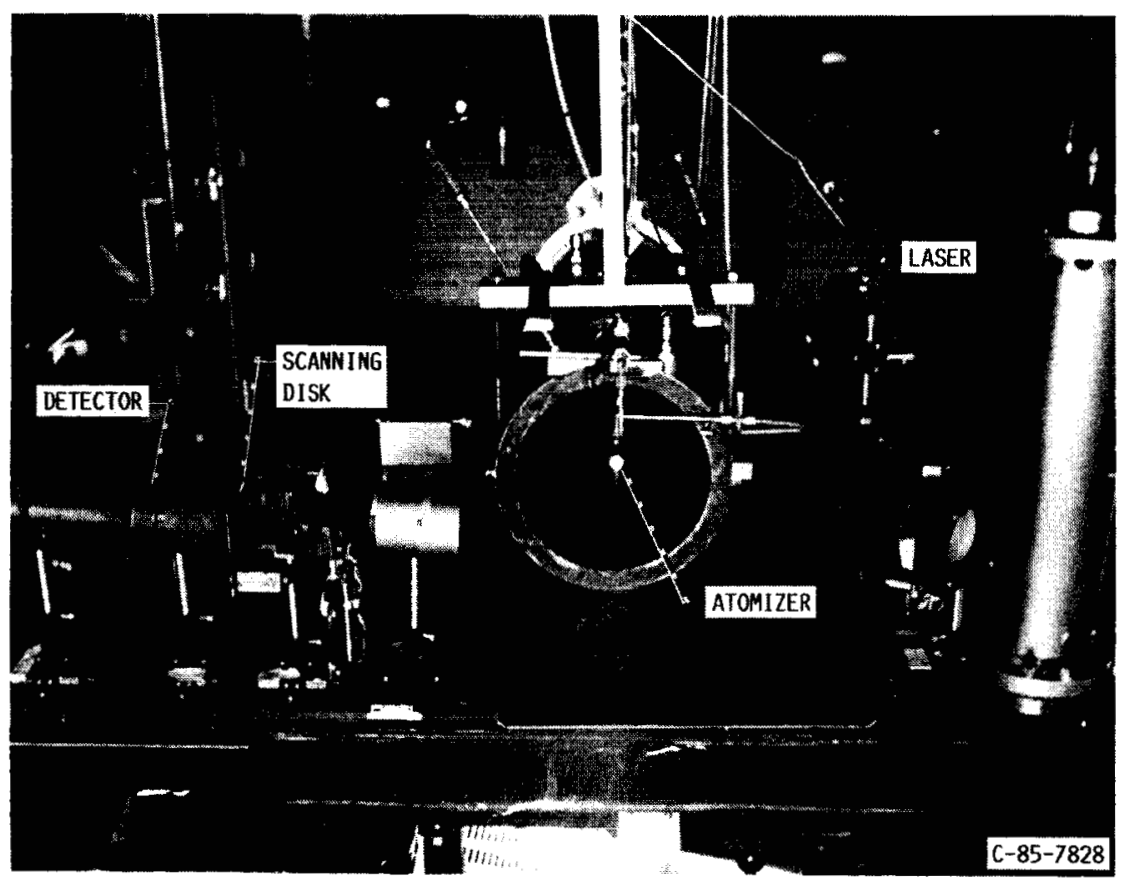

FIGURE 1. - APPARATUS AND AUXILL IARY EQUIPMENT.

CRITPRI PAEE IS OF POOR QUALITY

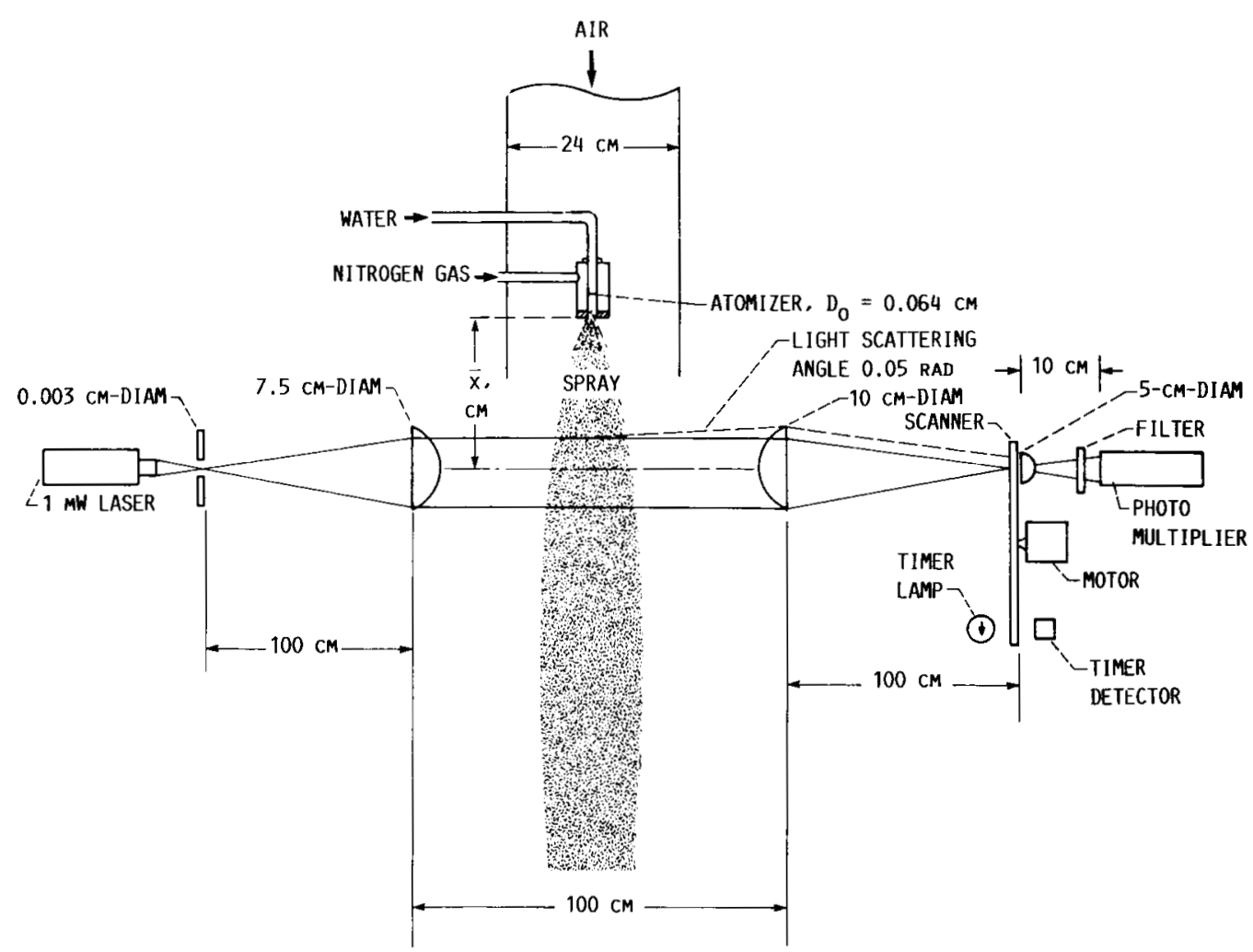

FIGURE 2. - ATMOSPHERIC PRESSURE TEST SECTION AND OPTICAL PATH OF SCATTERED-LIGHT SCANNER. 


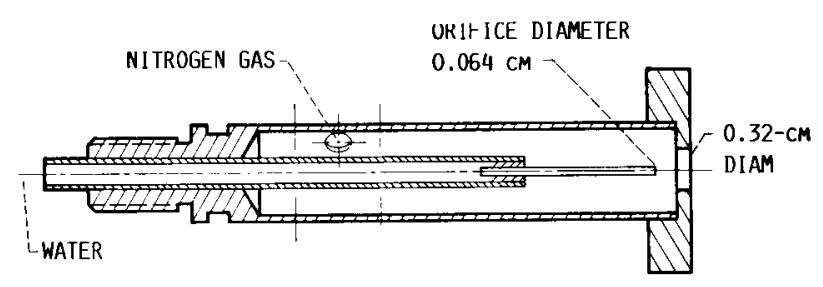

Figure 3. - Diagram OF PNEUMATIC TWO-FLUid ATOMIZER.
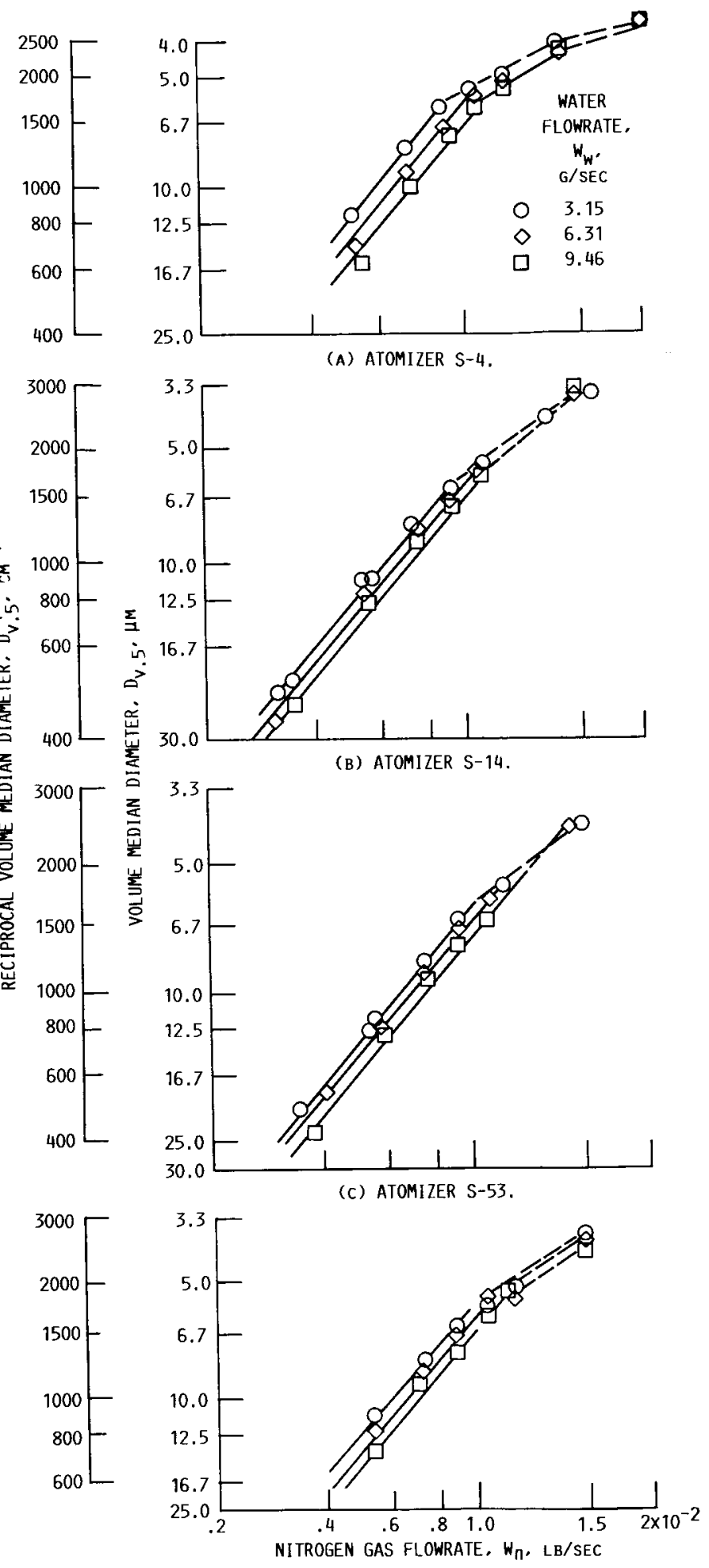

(D) ATOMIZER S-94.

FIGURE 4. - CORRELATION OF VOLUME MEDIAN DIAMETER D .5 WITH NITROGEN GAS FLOWRATE, $W_{n}$, AT $x=4.4 \mathrm{~cm}$. 


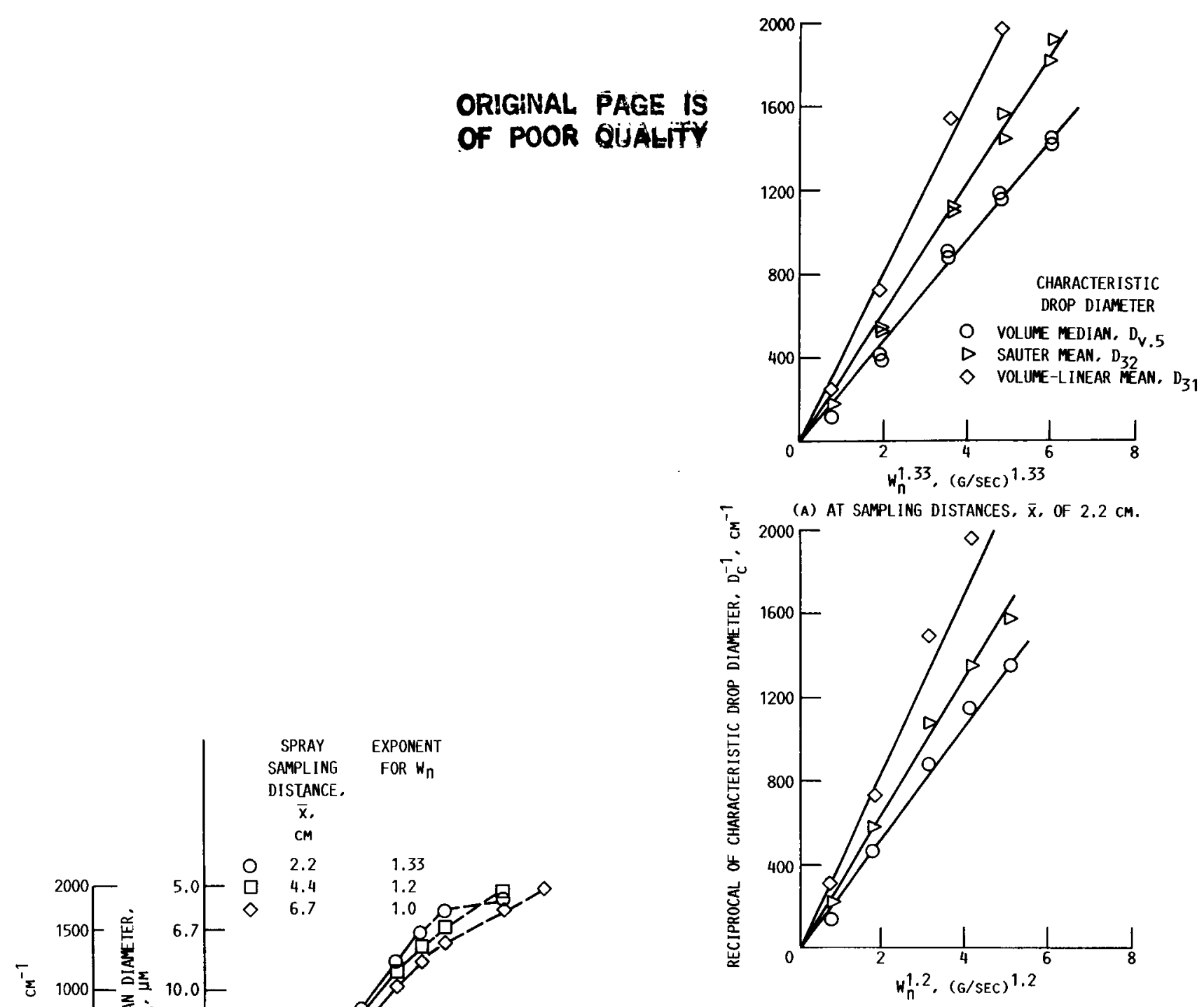

(B) AT SAMPLING DISTANCE, $\bar{x}$, OF $4.4 \mathrm{~cm}$.

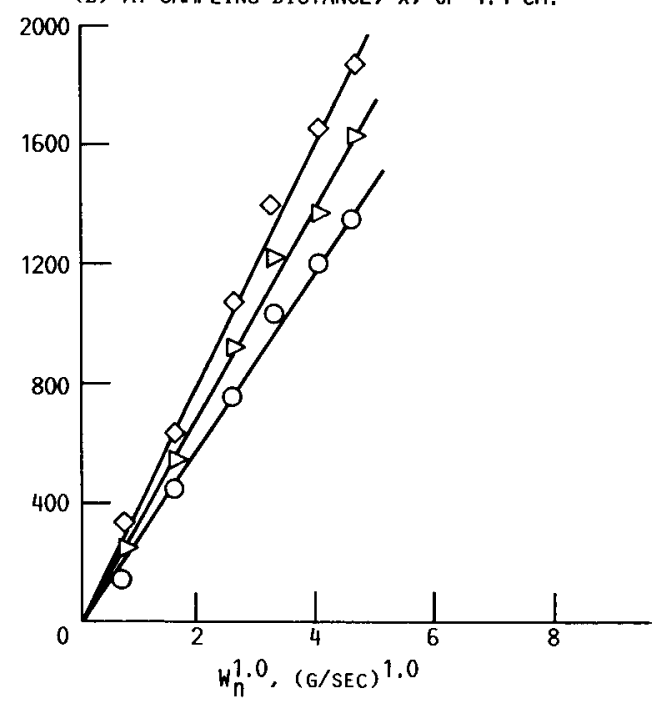

(c) AT SAMPLING DISTANCE, $\bar{x}$, OF $6.7 \mathrm{~cm}$.

FIGURE 6. - COMPARISON OF CHARACTERISTIC DROP DIAMETERS WITH ATOMIZER S-94 AND WATER FLOWRATE OF $3.15 \mathrm{G} / \mathrm{SEC}$. TERISTIC DROP DIAMETERS $D_{v .5}$ AND $D_{32}$ WITH $w_{w}=3.15$ G/SEC.

(A) VARIATION OF VOLUME MEDIAN, $D_{v, 5}$ WITH $W_{n}$; ATOMIZER S-53.

VARIATION OF SAUTER MEAN DIAMETER, $D_{32}$ WITH $W_{n}$; ATOMIZER S-94.

FIGURE 5. - EFFECT OF SPRAY SAMPLING DISTANCE $\bar{x}$ ON CHARAC- 


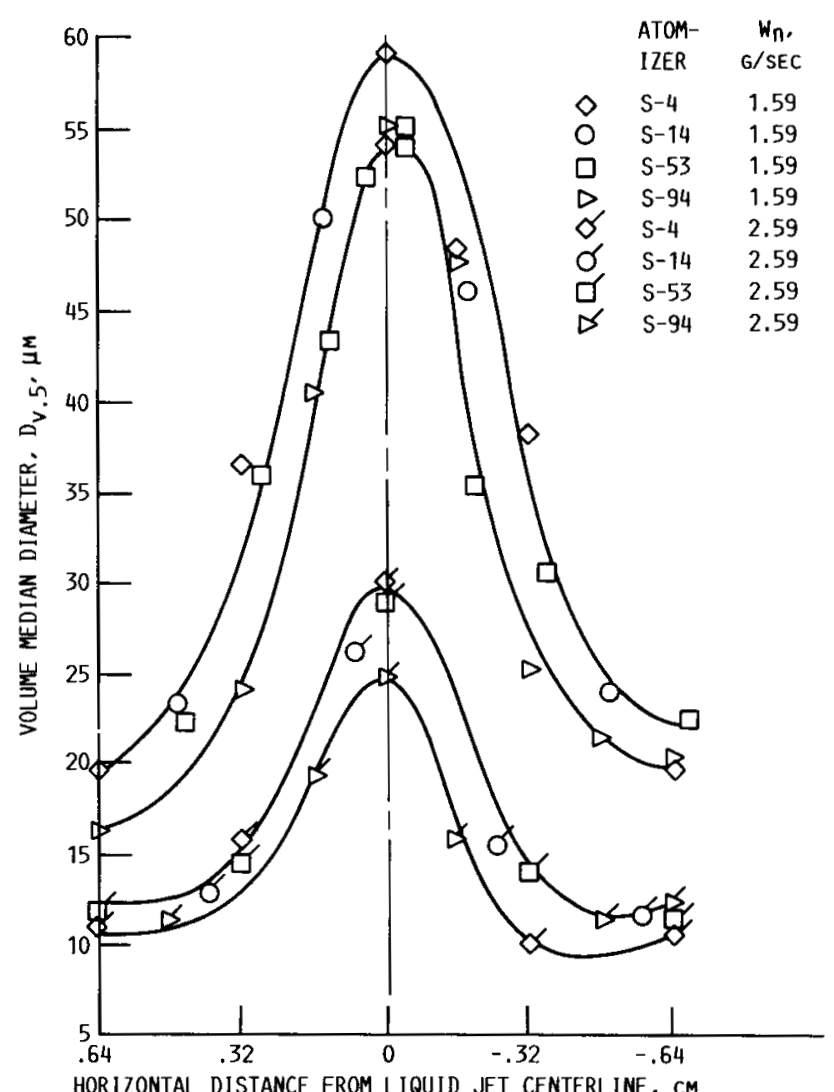

FIGURE 7. - SPRAY-PROFILE ENVELOPES FOR ATOMIZERS

AT $W_{W}=6.30 \mathrm{G} / \mathrm{SEC}$ AND $\bar{x}=4.4 \mathrm{~cm}$.

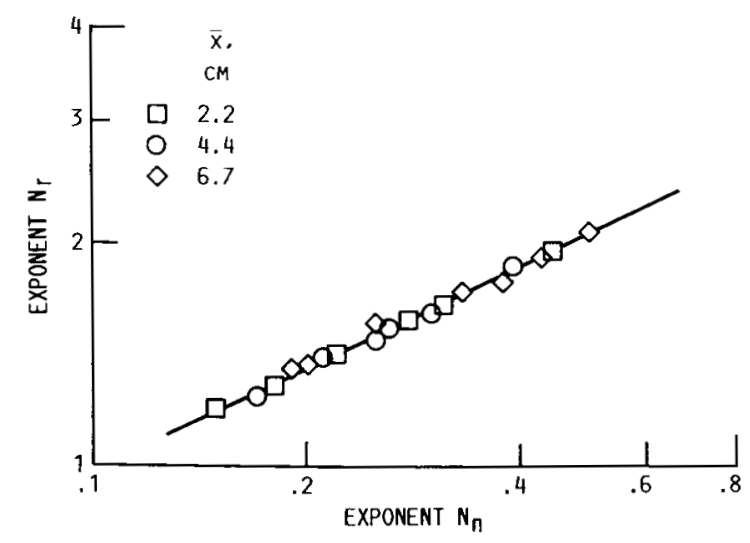

FIGURE 8. - CORRELATION OF ROSIN-RAMMLER AND NUKIYAMA-TANASAWA EXPONENTS $N_{r}$ AND $N_{n}$. RESPECTIVELY. 


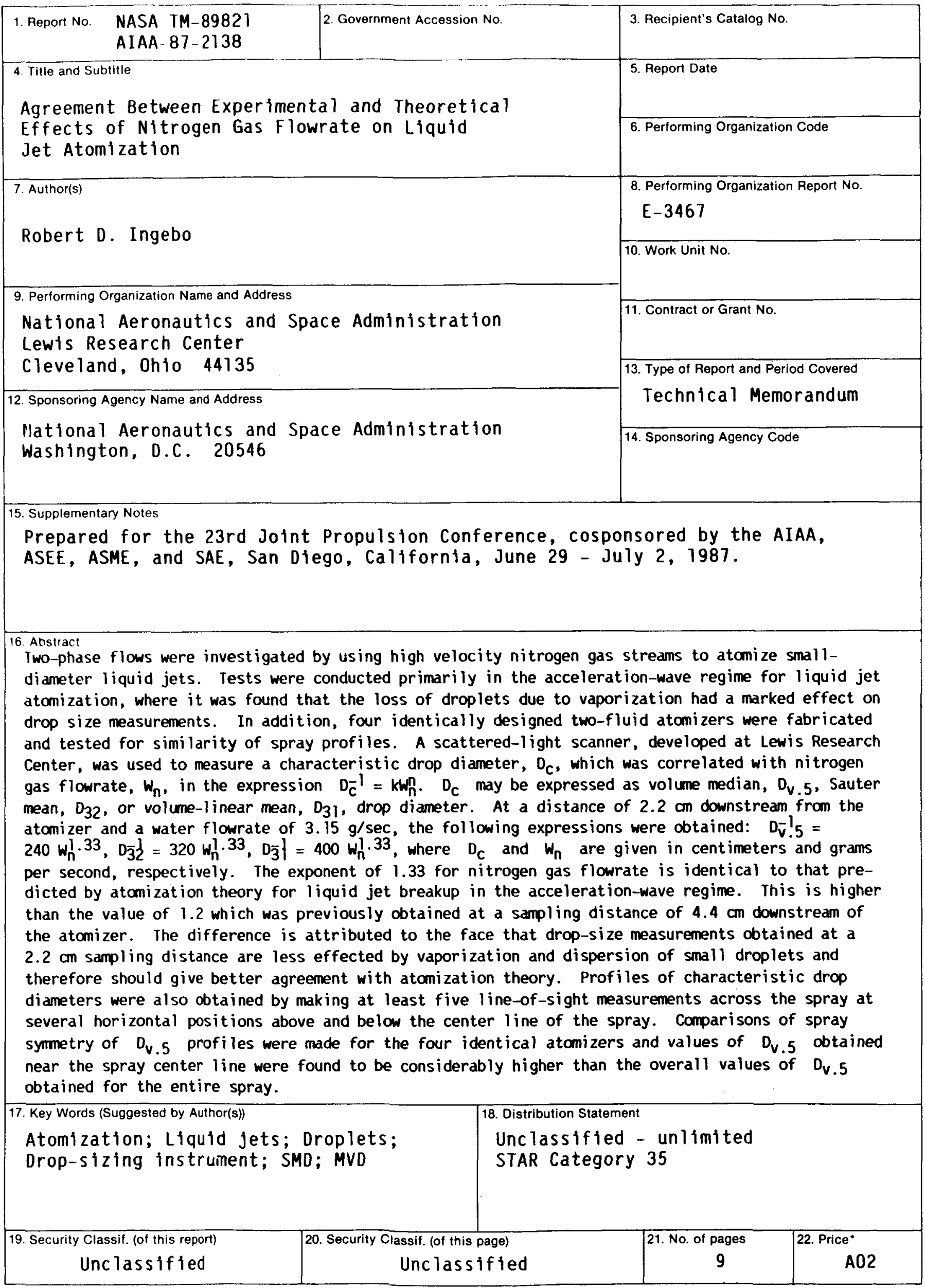

"For sale by the National Technical Information Service, Springfield, Virginia 22161 